NASA/TM-2004-212213

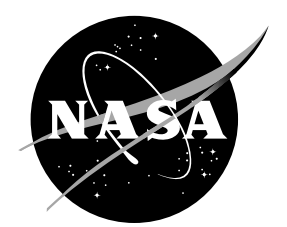

\title{
Properties of a Novel Ion-Exchange Film
}

Kenneth W. Street, Carol M. Hill, and Warren H. Philipp

Glenn Research Center, Cleveland, Ohio

Stephen P. Tanner

University of West Florida, Pensacola, Florida

Joseph Gorse, Amy Lusk, Jason Taylor, and Jason Dickens

Baldwin Wallace College, Berea, Ohio 
Since its founding, NASA has been dedicated to the advancement of aeronautics and space science. The NASA Scientific and Technical Information (STI) Program Office plays a key part in helping NASA maintain this important role.

The NASA STI Program Office is operated by Langley Research Center, the Lead Center for NASA's scientific and technical information. The NASA STI Program Office provides access to the NASA STI Database, the largest collection of aeronautical and space science STI in the world. The Program Office is also NASA's institutional mechanism for disseminating the results of its research and development activities. These results are published by NASA in the NASA STI Report Series, which includes the following report types:

- $\quad$ TECHNICAL PUBLICATION. Reports of completed research or a major significant phase of research that present the results of NASA programs and include extensive data or theoretical analysis. Includes compilations of significant scientific and technical data and information deemed to be of continuing reference value. NASA's counterpart of peerreviewed formal professional papers but has less stringent limitations on manuscript length and extent of graphic presentations.

- TECHNICAL MEMORANDUM. Scientific and technical findings that are preliminary or of specialized interest, e.g., quick release reports, working papers, and bibliographies that contain minimal annotation. Does not contain extensive analysis.

- CONTRACTOR REPORT. Scientific and technical findings by NASA-sponsored contractors and grantees.
- CONFERENCE PUBLICATION. Collected papers from scientific and technical conferences, symposia, seminars, or other meetings sponsored or cosponsored by NASA.

- SPECIAL PUBLICATION. Scientific, technical, or historical information from NASA programs, projects, and missions, often concerned with subjects having substantial public interest.

- TECHNICAL TRANSLATION. Englishlanguage translations of foreign scientific and technical material pertinent to NASA's mission.

Specialized services that complement the STI Program Office's diverse offerings include creating custom thesauri, building customized databases, organizing and publishing research results ... even providing videos.

For more information about the NASA STI Program Office, see the following:

- Access the NASA STI Program Home Page at http://www.sti.nasa.gov

- E-mail your question via the Internet to help@sti.nasa.gov

- Fax your question to the NASA Access Help Desk at 301-621-0134

- Telephone the NASA Access Help Desk at 301-621-0390

- Write to:

NASA Access Help Desk

NASA Center for AeroSpace Information 7121 Standard Drive

Hanover, MD 21076 
NASA/TM-2004-212213

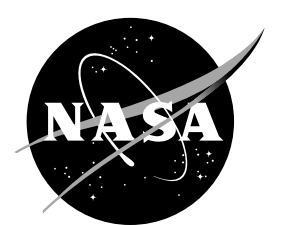

\section{Properties of a Novel Ion-Exchange Film}

Kenneth W. Street, Carol M. Hill, and Warren H. Philipp

Glenn Research Center, Cleveland, Ohio

Stephen P. Tanner

University of West Florida, Pensacola, Florida

Joseph Gorse, Amy Lusk, Jason Taylor, and Jason Dickens

Baldwin Wallace College, Berea, Ohio

National Aeronautics and

Space Administration

Glenn Research Center 


\section{Acknowledgments}

The authors greatly acknowledge Tim Dobrianski, Northeast Ohio Regional Sewer District, (electroplater waste solution and their confirmation analysis), Chemsultants, Inc. (fiberglass-reinforced IEM film), and Southwest Texas Research Institute (IEM powder).

This work was sponsored by the Low Emissions Alternative

Power Project of the Vehicle Systems Program at the NASA Glenn Research Center.

Trade names or manufacturers' names are used in this report for identification only. This usage does not constitute an official endorsement, either expressed or implied, by the National Aeronautics and Space Administration.

Available from

NASA Center for Aerospace Information 7121 Standard Drive

Hanover, MD 21076
National Technical Information Service 5285 Port Royal Road Springfield, VA 22100 


\title{
Properties of a Novel Ion-Exchange Film
}

\author{
Kenneth W. Street, Carol M. Hill, and Warren H. Philipp \\ National Aeronautics and Space Administration \\ Glenn Research Center \\ Cleveland, Ohio 44135 \\ Stephen P. Tanner \\ University of West Florida \\ Pensacola, Florida 32514 \\ Joseph Gorse, Amy Lusk, Jason Taylor, and Jason Dickens \\ Baldwin Wallace College \\ Berea, Ohio 44017
}

\begin{abstract}
A new ion-exchange material (based on polyacrylic acid) and some of its analytical applications have been reported. This paper contains data on the ion-exchange properties of the film form of the material and its potential application to the decontamination of waste water and drinking water. The film has a high exchange capacity of 5 to $6 \mathrm{meq} / \mathrm{g}$ and a $\mathrm{pK}_{\mathrm{a}}$ of 5.7. The calcium form is the most effective for removing metal ions from solution, and the optimum $\mathrm{pH}$ range is between 5 and 7 . The exchange rates are slower for the film than for bead and powder forms of the ion-exchange material; otherwise, the properties are similar. The film is effective when hard water solutions are employed and also when metal ions are in the complex matrix of waste water from electroplating. The film can be used in flow systems having a flow channel large enough to allow passage of turbid solutions.
\end{abstract}

\section{Introduction}

A novel cationic ion-exchange material (IEM) in film form is effective in removing metal cations from aqueous solution. ${ }^{1}$ The material is a nominal 1:1 blend of polyvinyl alcohol (PVA), used as a crosslinked support and antifouling agent, and polyacrylic acid (PAA), the active ion exchanger. Earlier versions of the IEM formed without PVA exchanged at the surface and then fouled quickly, preventing the use of the internal exchange sites. These versions of the film were cross-linked by electron-beam irradiation, a time-consuming, expensive method that frequently charred the product. It was found that a water-insoluble resin from the same PAA-PVA material could be made by chemical crosslinking with aldehydes. The current versions of the IEM are easily produced by environmentally friendly chemistry and include an optically transparent film. ${ }^{2-6}$ The new IEM has several advantages over commercial resins. For many of these resins, calcium, normally present in natural waters, competes with the metal ions, thus rendering the beads less effective for heavy-metal removal. However, one advantage of this new ionexchange material is that it is most effective for multivalent ions and is more durable when operating in the calcium form.

Reports in the literature have described the production ${ }^{3,5,6}$ and several applications ${ }^{1-3,7}$ of this ionexchange material (IEM). Although the IEM described in this paper is exclusively in the film form, the flexibility of the chemical processing to make the polymer permits it to be produced in other forms, including spherical beads, ${ }^{6}$ irregular granules, ${ }^{2}$ powder, ${ }^{4}$ fibers, coated magnetic particles, coatings on 
irregular objects, ${ }^{7}$ and fiberglass-reinforced film. ${ }^{8,9}$ The other forms appear to behave similarly to the material described herein although exceptions have been noted; for example, the operational $\mathrm{pH}$ range for the powder exchanging bound $\mathrm{Ca}^{2+}$ by $\mathrm{Cu}^{2+}$ is extended on the basic side and the kinetics are much faster.

To the best of our knowledge, commercial competing resins are not readily available in the form of films or coatings. Similar ion exchange beads are commercially available in several varieties. Some commercial products incorporating PAA and methacrylic acid have properties similar to this material. All these materials are weak acid exchangers that have similar $\mathrm{pK}_{\mathrm{a}}$ values and high capacities. Classes of ion exchangers with which these materials are typically compared also include the iminodiacetate chelating exchangers. Although some similarities exist, the chelating exchangers typically have extended $\mathrm{pH}$ operational ranges, different selectivity, and lower capacities. Films present some inherent advantages for the processing of waste materials, particularly where high particulate levels would render conventional packed column processing impossible. One example proposed was to decontaminate heavy-metal-laden sludge waste with a moving belt impregnated with an ion-exchange resin. ${ }^{10}$ We have used a similar approach involving a fiberglass-reinforced film to decontaminate electroplating waste solutions. ${ }^{9}$

We report efforts to characterize the IEM, especially in the film form. This material was tested with a large number of metal ions. Also reported are its capacity, measured absorption rates and equilibrium conditions, multielement studies, and operating $\mathrm{pH}$ range for various metals. The application of the film to the removal of metal ions from various waste solutions is described.

\section{Experimental}

\section{Apparatus}

The metal ion concentrations in most solutions were determined using an atomic absorption spectrophotometer (AAS) set up for flame analysis or equipped with a graphite furnace. Yttrium ion concentration was measured on an inductively coupled plasma atomic emission spectrometer (ICP). A cold vapor atomic absorption spectrophotometer (CVAA) was used for mercury determination. In all cases, the instrument calibration was based on commercial standards containing $1000 \mathrm{ppm}$ of the desired metal serially diluted with 5-percent nitric acid. Infrared spectra were recorded on an FT-IR instrument with IEM films in transmission mode. All pH measurements were made using a pH meter with a combination glass electrode calibrated with two buffers. In the kinetic studies, solutions were stirred at $200 \mathrm{rpm}$ under similar conditions using an electronic stirrer with eight satellite stirrers.

\section{Reagents and IEM}

Polyvinyl alcohol (molecular weight of 108 000) was obtained from Polysciences, Inc. and polyacrylic acid (molecular weight of 450 000) from Aldrich Chemical Company. Certified glutaraldehyde (50 wt \%) and formaldehyde (37 wt \%) from Fisher Scientific were used as received. All metal salts and acids were AR-grade chemicals from Fisher Scientific or Mallinckrodt. All solutions were prepared with deionized water. The conditions for the preparation of the IEM film used throughout these experiments are described in the literature. ${ }^{3}$ The films for IR studies were prepared by casting a 10-percent mixture (1:1 PVA-PAA) containing enough glutaraldehyde to cross link $7.5 \mathrm{~mol} \%$ of the alcohol sites of the PVA component of the IEM. The liquid layer was allowed to dry at room temperature overnight and was then heated in an oven at $40^{\circ} \mathrm{C}$ for $1 \mathrm{hr}$ to finish the crosslinking, thus producing $10-\mu \mathrm{m}$ - thick films. 


\section{Procedures}

Analysis procedures. - The concentrations of metals on the IEM films were determined after either destructive digestion of the IEM or back extraction of the metals into 10-percent $\mathrm{HCl}$. The concentrations were determined according to the EPA procedures for the determination of trace metal ions. ${ }^{11}$ Back extraction with 10-percent acid solution yielded results equivalent to the digestion procedure.

$\mathrm{pH}$ study of metal ion exchange.- - Samples containing $50 \mathrm{ml}$ of $15-\mathrm{ppm}$ solutions of different metal ions were prepared and the solutions were adjusted to the desired $\mathrm{pH}$ value using $\mathrm{HNO}_{3}$ or $\mathrm{NaOH}$. Small aliquots were taken initially and at various times and were acidified with $\mathrm{HNO}_{3}$ and set aside for later analysis. After $24 \mathrm{hr}$, the film was removed, the final $\mathrm{pH}$ of the system was measured, and $1 \mathrm{ml}$ of concentrated $\mathrm{HNO}_{3}$ was added to the solution, which was saved for further analysis.

IEM capacity.-The capacity was determined by back titration. Accurately weighed pieces $(100.0 \mathrm{mg})$ of the IEM in acid form were allowed to equilibrate with $10.00 \mathrm{ml}$ of standardized $0.1000 \mathrm{M} \mathrm{NaOH}$ solution. After stirring for several hours, the film was removed and the excess base titrated with standard $0.0500 \mathrm{M} \mathrm{HCl}$. The $\mathrm{pH}$ was measured on a $\mathrm{pH}$ meter and a standard $\mathrm{pH}$ titration plot of $\mathrm{pH}$ versus volume titrant was used to determine the two end points of the titration. The first end point corresponds to excess hydroxide and the second to PAA that had leached from the film.

IEM $\mathrm{pK}_{\mathrm{a}}$ determination.-The $\mathrm{pK}_{\mathrm{a}}$ of the IEM was determined by $\mathrm{pH}$ titration. Because of the slowness of the equilibration reaction, the titration curve was obtained by the addition of different volumes of $0.1000 \mathrm{M} \mathrm{NaOH}$ (ranging from $1.00 \mathrm{ml}$ to a volume beyond the equivalence point) to pieces of exactly the same mass of film $(200.0 \pm 0.4 \mathrm{mg})$. In each case, the total volume was adjusted to $40.00 \mathrm{ml}$ with $0.100 \mathrm{M} \mathrm{NaCl}$, bringing each solution to an ionic strength of $0.100 \mathrm{M}$. The solutions were stirred overnight, the $\mathrm{pH}$ was measured, and a titration curve was constructed.

Proton exchange rates. - The rate of exchange of hydrogen ions on the film by sodium ions was determined by the following procedure. A series of $121 \pm 1-\mathrm{mg}$ pieces of film (approx. $4 \mathrm{~cm}^{2}$ or $0.65 \mathrm{meq}$ ) in the hydrogen form were added to $50 \mathrm{ml}$ of solutions consisting of $0.020 \mathrm{M} \mathrm{NaOH}$ and $0.10 \mathrm{M} \mathrm{NaCl}$. The solutions were stirred and the films were removed at different times that ranged from 2 to $40 \mathrm{~min}$. The solutions were then titrated with standard $0.10 \mathrm{M} \mathrm{HCl}$ to a methyl red end point. The reverse reaction in which sodium ions on the film are replaced by hydrogen ions was studied by a similar procedure. In these experiments, $121 \pm 1-\mathrm{mg}$ pieces of the sodium form of the film were added to $50-\mathrm{ml}$ volumes of $0.04 \mathrm{M} \mathrm{HCl}$ and $0.06 \mathrm{M} \mathrm{NaCl}$ and were stirred. The pieces of film were removed at 1-min intervals and the solutions titrated with standard $0.10 \mathrm{M} \mathrm{NaOH}$ solution to a phenolphthalein end point.

Cation sorption rates.- Kinetics studies ${ }^{1,12}$ on the exchange of calcium ions or sodium ions on the film by other metal ions were conducted using a procedure similar to that used in the $\mathrm{pH}$ studies described in the previous section. Small aliquots were removed and acidified at various time intervals.

Recycling study. - Five pieces of acid film, $200 \mathrm{mg}$ each, were stirred with excess $\mathrm{Ca}(\mathrm{OH})_{2}$ slurry to convert them to the $\mathrm{Ca}^{2+}$ form. The excess $\mathrm{Ca}(\mathrm{OH})_{2}$ was rinsed and the film was stirred with a small excess of standard $\mathrm{HCl}$. After equilibration, the excess $\mathrm{HCl}$ was rinsed from the film and determined by titration with standard $\mathrm{NaOH}$ to a phenolphthalein end point. This process was repeated 10 times with each film. A second series of films were tested using excess $\mathrm{NaOH}$ for conversion to the $\mathrm{Na}^{+}$form.

Comparative resin study.-Two samples (130 mg each) of hydrogen-form Fisher Amberlite IR-120 16- to 50-mesh ion-exchange beads and BIO-RAD AG 50W-X8 200- to 400-mesh ion-exchange beads were equilibrated with $2 \mathrm{M} \mathrm{CaCl}_{2}$ to obtain the calcium form and with $1 \mathrm{M} \mathrm{NaCl}$ to obtain the sodium form. The beads were then washed with deionized water and transferred to copper solutions $(200 \mathrm{ml}$ of 15-ppm $\mathrm{Cu}^{2+}$ ), which were stirred for $24 \mathrm{hr}$. Several 4-ml samples (in addition to a 4-ml final solution sample) were removed during the $24 \mathrm{hr}$ (noting the time of removal), preserved with $0.1-\mathrm{ml}$ concentrated $\mathrm{HNO}_{3}$, and set aside for later AAS analysis. A plot of concentration versus time was constructed.

Electroplater's waste study.-A large waste water sample from a local electroplating industry was obtained from the Northeast Ohio Regional Sewer District in Cleveland, Ohio. This waste contained a 
mixture of metals at various concentrations, including sodium, copper, zinc, cadmium, and others. The sample consisted of a large amount of precipitated material and the clear liquid above the precipitate. Two 100-ml samples of this clear liquid were removed and diluted to $1000 \mathrm{ml}$ with water. The $\mathrm{pH}$ of one of these samples was then adjusted to 5 , and the $\mathrm{pH}$ of the other was adjusted to 7 . The waste water sample was then shaken vigorously, and a 150-ml sample of the now cloudy liquid was removed. The $\mathrm{pH}$ was adjusted to 1 with concentrated $\mathrm{HNO}_{3}$, and the sample was then filtered twice to remove the remaining precipitates. A 100-ml sample of the filtered solution was then diluted to $1000 \mathrm{ml}$, and the $\mathrm{pH}$ was approximately 2 .

A $25-\mathrm{ml}$ initial sample of each solution was removed, preserved with $0.1-\mathrm{ml}$ concentrated $\mathrm{HNO}_{3}$, and set aside for later ICP analysis. A 600-mg piece of dried, weighed film in the calcium form was added to the beakers with a stir bar and the solution was stirred for $48 \mathrm{hr}$. Samples ( $25 \mathrm{ml}$ each) were removed after $1,3,5,24$, and $48 \mathrm{hr}$ and were preserved with $0.1-\mathrm{ml} \mathrm{HNO}_{3}$. These samples were analyzed by the ICP. A table of the adsorption properties of the IEM in a mixture of metals at each $\mathrm{pH}$ value was constructed.

Spiked electroplater's waste study.-A 100-ml sample of the clear liquid from the electroplating industry waste water sample, spiked to $15 \mathrm{ppm}$ with copper, was diluted to $1000 \mathrm{ml}$, and the $\mathrm{pH}$ was adjusted to 5. A 25-ml initial sample was removed and preserved as in the previous waste water experiment. A 600-mg piece of film was added to the solution and samples were removed and analyzed as described in the previous section. A graph of the uptake of copper versus time was constructed for the spiked mixture and a similarly treated $\mathrm{Cu}^{2+}$ aqueous standard.

Column experiment.- To simulate a continuous process, a long length of 2.54 -cm-wide formaldehyde cross-linked film converted to the calcium form was spirally wrapped about an 8.1-mmdiameter glass rod, which was polished at both ends. At the end of the strip of film, another film was started such that the entire 91.4-cm rod (3 ft) was coated with IEM. The rod was inserted in a vertical glass tube having an inside diameter of $9.3 \mathrm{~mm}$. The rod was held in place with Swagelok fittings that were reduced to $1 / 16$ in. outside-diameter tubing for connection to a HPLC pump. Copper (16.8 ppm) and lead (142 ppb) challenge solutions (fortified tap water) were pumped upward through the annulus of the column at $0.1 \mathrm{ml} / \mathrm{min}$ and were collected at the effluent end of the rod at various intervals for analysis. In a second series of experiments, a $45.7-\mathrm{cm}(1.5 \mathrm{ft})$ section of similar rod was dip coated in an IEM mixture containing enough glutaraldehyde to cross-link $7.5 \mathrm{~mol} \%$ of the alcohol sites of the PVA component of the IEM. This rod was allowed to dry upright at room temperature overnight, after which it was heated in an oven at $40{ }^{\circ} \mathrm{C}$ for $1 \mathrm{hr}$ to finish the crosslinking, which produced a $5-\mu \mathrm{m}$-thick film. The film was converted to the calcium form (subsequently, this wet film was measured to be $10 \mu \mathrm{m}$ thick). This rod was inserted in a tube similar to that described for the 91.4-cm rod. The challenge solution for this system was tap water fortified to 9.0-ppm copper run at a flow rate of $0.5 \mathrm{ml} / \mathrm{min}$ for $390 \mathrm{~min}$ and then at $1.0 \mathrm{ml} / \mathrm{min}$ for an additional $355 \mathrm{~min}$.

\section{Results and Discussion}

\section{Acid-Base Properties}

The $\mathrm{pK}_{\mathrm{a}}$ of $5.70 \pm 0.05$ for the IEM was determined at the point in figure 1 where the fraction of conversion was 0.5 . This compares with a $\mathrm{pK}_{\mathrm{a}}$ of 5.45 for polyacrylic acid itself, determined under the same conditions. Figure 1 indicates the equilibrium $\mathrm{pH}$ over the film at various stages of conversion from the acid form to the salt form. Also shown in the figure for comparison are the powder ${ }^{4}$ and the fiberglass-reinforced film, ${ }^{9}$ both of which were cross-linked with glutaraldehyde such that 7.5 percent of the PVA alcohol sites are reacted during the cross-linking procedure. 
From back titration, the capacity of the hydrogen form was determined to be $5.78 \pm 0.19 \mathrm{meq} / \mathrm{g}$. Titration of the film using $\mathrm{NaOH}$ converts the film to the $\mathrm{Na}$ form and expands its size by more than 40 percent. The expansion causes the rapid deterioration of the film. Fortunately, the IEM is used in the $\mathrm{Ca}$ form and a similar titration with $\mathrm{Ca}(\mathrm{OH})_{2}$ does not cause the deterioration or leakage described in earlier works. ${ }^{3,4}$ Five pieces of IEM were cycled through Ca charging followed by reconversion to the acid form 10 times, and the results are presented in figure 2. No deterioration of the films was noted during the recycling and the capacities determined were typical of this IEM. Typical capacities range from 5 to $6 \mathrm{meq} / \mathrm{g}$ between different lots. The average initial capacity was determined to be $5.3 \mathrm{meq} / \mathrm{g}$ and the average leakage and/or loss in capacity was determined to be $0.02 \mathrm{meq} / \mathrm{g} / \mathrm{cycle}(0.4$ percent per cycle). The capacity was also determined by allowing weighed amounts of the calcium form of the film to equilibrate with solutions containing an excess of the metal ion. The concentration of the $\mathrm{Zn}^{2+}$ in solution was determined before and after equilibration and the capacity calculated. To insure complete equilibration, $24 \mathrm{hr}$ elapsed before the final concentrations were measured. These measured capacities $(5.2 \mathrm{meq} / \mathrm{g})$ were in close agreement with the value obtained by titration of the acid form of the film. Similar results have been demonstrated for $\mathrm{Cu}^{2+}$ uptake on IEM beads. ${ }^{4}$

Since the material is a weak acid, its ion-exchange properties depend on the $\mathrm{pH}$. Figure 3 shows the $\mathrm{pH}$ dependence of metal uptake for lead, cadmium, copper, mercury, and zinc. At lower $\mathrm{pH}$ 's, the metal ion uptake increases with $\mathrm{pH}$ as the fraction of resin in the calcium form increases (see fig. 1). The decrease at higher $\mathrm{pH}$ 's is a consequence of the hydrolysis of the metal ions. The ion exchange is most effective in the $\mathrm{pH}$ range of 5 to 7, and therefore the kinetic and equilibrium studies were performed within this range.

The IEM can be recycled after loading with metal ions. To accomplish stripping, we typically use a sufficient volume of 10-percent $\mathrm{HNO}_{3}$ (for metals producing insoluble chlorides) or $\mathrm{HCl}$, producing a final $\mathrm{pH}$ of 0 to 1 . We have determined that complete recovery from the film occurs within 2 to 3 min with stirring. The only metal tested that was not completely recovered from these films was chromium (III), which initially turned the film violet and eventually turned it gray. We have films containing copper, cobalt, nickel, and others that have retained their original color (the color of the hydrated metal ion) for many years. ${ }^{1}$

\section{Affinity for Metal Cations}

The relative affinity of the calcium form of the film for a series of metal ions is

High affinity for IEM

$$
\begin{aligned}
\mathrm{Pb}^{2+}>\mathrm{Cd}^{2+}>\mathrm{Cu}^{2+} \sim\left(\mathrm{Ln}^{3+} \mathrm{s}^{3+}\right)>>\mathrm{Cr}^{3+}>\mathrm{Ni}^{2+} \sim\left(\mathrm{Zn}^{2+}\right) \sim \mathrm{Co}^{2+}> & \\
\mathrm{Hg}^{2+} \sim\left(\mathrm{Ag}^{+}\right)>\left(\mathrm{Ba}^{2+}\right)>\mathrm{Ca}^{2+}>\left(\mathrm{Mg}^{2+}\right)>\mathrm{Fe}^{3+} \sim\left(\mathrm{Na}^{+}\right) & \text {Low affinity for IEM }
\end{aligned}
$$

This order was determined by allowing a piece of film to equilibrate with a solution containing equimolar concentrations of metal ions at a $\mathrm{pH}$ of 5.5 where the concentration of ions greatly exceeded the capacity of the resin used. The series were established by measuring the initial and final concentrations. Metals appearing in parentheses are approximate locations and were not tested in this experiment. These metals have been added to the series based on information acquired from other testing studies. The exchange constants $\mathrm{K}_{\mathrm{ex}}$ for $\mathrm{Ba}^{2+}$ and $\mathrm{Mg}^{2+}$ on calcium films were determined to be 1.06 and 0.37 , respectively. For metals high in the series, exchange with an excess of the calcium film resulted in final metal ion concentrations at or below AAS detection limits. 
Since the affinities of metal ions for the IEM vary with $\mathrm{pH}$ as shown in figure 3, inferences based on the above series can be misleading. For example, the series suggests that $\mathrm{Hg}^{2+}$ would not be taken up well by the IEM; however, at a $\mathrm{pH}$ of 6 to 7 , the IEM is effective at removing mercury from solution. In a second example, tests showed that silver is more effectively removed by the sodium form of the IEM that has proven to be less effective at removing divalent metal ions. The value of the selectivity series is that it provides the reader with a means to determine the approximate affinity of the IEM for a particular set of cations.

Some of the selectivity is readily explained by a comparison of stability constants for model ligands on several select metals. ${ }^{13}$ For acetate complexation to metals $\mathrm{Cu}, \mathrm{Pb}, \mathrm{Zn}$, and $\mathrm{Ca}$, the stability is in the order $\mathrm{Pb}>\mathrm{Cu}>\mathrm{Zn}>>\mathrm{Ca}$. As the IEM has adjacent carboxylate groups on a straight-chain hydrocarbon backbone, better models for ligands would include succinic acid or a short-chain ligand with a rigid bridge on the chain between the functional groups such as citraconic acid. For these ligands, the approximate order of stability (based on $\mathrm{K}_{\mathrm{fl}}$ ) is $\mathrm{Pb}=\mathrm{Cu}>$ (or perhaps $>>$ ) $\mathrm{Zn}>\mathrm{Ca}$. None of these multidentate ligand models adequately explains the exceptional preference of the IEM for $\mathrm{Pb}$ over $\mathrm{Cu}$. Added insight can be gained by an examination of the IR spectra of these complexes.

\section{Infrared Spectroscopic Studies}

The IEM is composed of polymers containing both carboxylic acid and alcohol groups. Therefore, the IR spectrum is a combination of the absorption bands commonly found in each of these molecules in addition to the bands introduced into the polymer because of the crosslinking of the PVA with aldehyde. The primary absorption bands of concern in this study are those of the polyacrylic acid component responsible for the ion exchange. The strong carbonyl absorption band in a dimerized carboxylic acid is typically found between 1700 to $1725 \mathrm{~cm}^{-1}$. When IR spectra were taken of IEM films that had sorbed metal ions, the two new peaks that appeared indicated the formation of the carboxylate ion. The carboxylate ion gives rise to an asymmetric stretching band between 1550 to $1650 \mathrm{~cm}^{-1}$ and a symmetric stretching band near $1400 \mathrm{~cm}^{-1}$. The frequency of each of these two bands varies slightly depending on the metal that is sorbed to the film. Nakamoto and Tackett both reported IR investigations on metal acetates to gain a better understanding of metal-carboxylate interactions. ${ }^{14,15}$ In order to explain IR shifts, they proposed four types of interactions: ionic, unidentate, bidentate, and bridging. These interactions can be distinguished in the IR by the wave number difference between the carboxylate asymmetric and symmetric stretches. The frequency separation between these bands $\delta v$ was 30 to $160 \mathrm{~cm}^{-1}$ for ionic interactions, usually greater than $200 \mathrm{~cm}^{-1}$ for unidentate interactions, less than $90 \mathrm{~cm}^{-1}$ for bidentate interactions, and 140 to $170 \mathrm{~cm}^{-1}$ for bridging interactions. ${ }^{14}$ In the reported studies, crystalline and aqueous metal acetates were used to determine the relationships, neither of which directly applies to resin studies. In spite of this, we believe that the difference between the IR bands in the IEM should be a constant $\delta v$ for ionic interactions such as the alkali metals ( $\mathrm{Li}, \mathrm{Na}, \mathrm{K}$ ). For metals with a low formation constant such as $\mathrm{Mg}, \mathrm{Ca}$, and $\mathrm{Zn}, \delta \mathrm{v}$. values with carboxylate groups should also be constant. The observed shift for these metals ranges from 129 to $150 \mathrm{~cm}^{-1}$. It is not possible to determine if complexation is involved with metals having similar IR shifts; however, when significant departures from this range are involved, it is realistic to associate the shift with complexation. For example, two different experiments performed with $\mathrm{Cu}$ produced shifts of 171 and $204 \mathrm{~cm}^{-1}$, whereas $\mathrm{Pb}$ and $\mathrm{Cd}$ had shifts of 86 and $107 \mathrm{~cm}^{-1}$, respectively. The IR interpretation of the coordination with $\mathrm{Cu}$ would suggest that each ligand only has one point of attachment to the metal (unidentate), whereas each ligand has two points of

attachment (bidentate) for $\mathrm{Pb}$ and perhaps $\mathrm{Cd}$. This would explain why the $\mathrm{Pb}$ and $\mathrm{Cd}$ are attracted to the IEM more strongly than $\mathrm{Cu}$. For $\mathrm{La}$, the symmetric and asymmetric stretch frequencies are 1419 and $1542 \mathrm{~cm}^{-1}$, respectively. Using the data in reference $15 \mathrm{for} \mathrm{cm}^{-1}$ versus ionic radii, these values also suggest bidentate interaction. This is consistent with information obtained for $\mathrm{Tb}$ from luminescent 
lifetime measurements, ${ }^{12}$ which indicate that only three water molecules remain coordinated to $\mathrm{Tb}^{3+}$ when it is bound to the IEM. Assuming a normal coordination number of nine for $\mathrm{Tb}^{3+}$, then six of the coordination sites must be taken up by three carboxylate groups. Because of this strong complexation, the IEM film will remove lanthanide ions from solutions of parts-per-billion levels as reported in earlier studies.

\section{Kinetic Studies}

When the hydrogen form of the film is treated with $0.02 \mathrm{M} \mathrm{NaOH}$ in the presence of $0.1 \mathrm{M} \mathrm{NaCl}$, 50 percent of the hydrogen ions are replaced by sodium ions in about $7 \mathrm{~min}$. The reverse reaction in which sodium ions are replaced by hydrogen ions from $0.04 \mathrm{M} \mathrm{HCl}$ has a halflife of about $1 \mathrm{~min}$. For sulfonate resins in bead form, the half- lives for the exchange of hydrogen ions by sodium ions range from less than $4 \mathrm{sec}$ to about $50 \mathrm{sec}$, depending on the bead size and degree of crosslinking. ${ }^{16}$ For these beads, the reverse reaction, the replacement of sodium ions by hydrogen ions, is slower ${ }^{17}$ by a factor of 2 . With the IEM, the opposite was observed. Under the conditions of our experiments, the exchange of hydrogen ions by sodium ions is slower than the reverse reaction. This result is not unexpected in that the IEM is a weak acid exchanger and requires the involvement of hydroxide ions when the acid form is converted to the sodium form. The generally slow exchange reactions of the IEM film are a consequence of the low surface area rather than the properties of the material itself. As expected, in the powder form, IEM exchange rates are much faster. ${ }^{4}$

In the experiments in which calcium or sodium ions on the film were exchanged by other test metal ions, the exchange capacity of the IEM was in excess of the test ions by a factor of at least 7 . When lead and zinc were the test metals, the solutions were buffered with hexamethylenetetramine to maintain the $\mathrm{pH}$ and to prevent hydrolysis. The buffer had a negligible effect on the exchange rate or equilibrium concentrations of these metal ions.

The rates of metal ion uptake by calcium and sodium films, as measured by the depletion of the test metal ion concentration over the films, are shown in figures 4 to 7 . For reactions in which the calcium or sodium ions are replaced by ions of a similar charge (e.g., fig. $4, \mathrm{~Pb}^{2+}$ replacing $\mathrm{Ca}^{2+}$ or fig. $5, \mathrm{Ag}^{+}$ replacing $\mathrm{Na}^{+}$), the reactions follow first-order kinetics for several halflives. In systems in which ions of a different charge are involved, the uptake curves exhibit a discontinuity after about 1 to 2 halflives. When a monovalent such as silver replaces the divalent calcium ion, the IEM film increases substantially in volume. A reduction in volume is observed when a divalent such as copper replaces a monovalent like sodium. The discontinuity and size changes suggest that the exchange of ions of different charges causes greater structural changes than the exchange of similarly charged ions. An extreme example of this discontinuity is the uptake of yttrium by a sodium film (fig 6). In this reaction, the equilibrium concentration of $\mathrm{Y}^{3+}$ after 45 halflives is higher than that measured at intermediate times.

The halflives for metal ion exchange with calcium and sodium film are given in table 1. For the reactions exhibiting discontinuities in the plots of concentration versus time, halflives were determined from data up to about 1 halflife. The exchange rates of the different metal ions follow the general trend of the hydrated metal ion radii: the smaller the radius, the faster the exchange process. The calcium film takes up divalent ions more slowly than the sodium film, but the final concentrations of test metal ions over the calcium film are lower than those over the sodium films. On the other hand, for the univalent $\mathrm{Ag}^{+}$, exchange with the sodium film is faster and the final equilibrium concentration of $\mathrm{Ag}^{+}$is lower than that with the calcium film.

Figure 7 shows the uptake of $\mathrm{Cu}^{2+}$ from a solution containing 100-ppm $\mathrm{Ca}^{2+}\left(\mathrm{as} \mathrm{CaCl}_{2}\right)$ in comparison with a solution containing only $\mathrm{Cu}^{2+}$. The halflife and equilibrium data are included in table 1 . With calcium film in the presence of $100-p p m \mathrm{Ca}^{2+}$, the rates of uptake of $\mathrm{Cu}^{2+}\left(\right.$ and not shown $\left.\mathrm{Cd}^{2+}\right)$ are slower, but within experimental error, the equilibrium concentrations are not affected. When sodium film is used in the presence of 100 -ppm excess $\mathrm{Ca}^{2+}$, the initial rates of uptake of both $\mathrm{Cu}^{2+}$ and $\mathrm{Cd}^{2+}$ are 
similar to the rates for sodium films with no added $\mathrm{Ca}^{2+}$. As the reaction proceeds, the $\mathrm{Na}^{2+}$ ions on the film are replaced by $\mathrm{Ca}^{2+}$, the rate of test metal uptake slows, and the final equilibrium concentrations are the same as those attained when a calcium film is used.

A calcium concentration of $100 \mathrm{ppm}$ corresponds to a total water hardness of $250 \mathrm{ppm}$ based on calcium carbonate. This demonstrates that the ion-exchange material is effective in removing metal ions from hard water. In a 1000-ppm calcium solution, the final equilibrium concentration of $\mathrm{Cu}^{2+}$ was slightly higher, indicating that the $\mathrm{Ca}^{2+}$ was beginning to compete with the uptake of $\mathrm{Cu}^{2+}$.

Commercially available, strong acid ion-exchange resin beads also remove metal ions from aqueous media when used in the sodium form and have capacities comparable to this IEM. However, they are not as efficient in the calcium form. For comparison, the results of the kinetic study of two such resin beads illustrate this point, as can be seen in figure 8 . There is a reversal in the equilibrium concentrations of the calcium and sodium curves as compared with the uptake curves of the new IEM (figs. 4, 6, and 7). Calcium ions compete with other metals such as lead, cadmium, or copper for the exchange sites on the commercial resins studied, and this competition reduces their effectiveness in hard water. The fact that they have faster rates of metal ion uptake is attributed to mass diffusion in solution. In other investigations with IEM beads and powder, ${ }^{4}$ the IEM was demonstrated to remove metal ions from solution at least as rapidly as these commercial resins. Under hard water conditions, a more appropriate comparison of the IEM would be to other chelating resins such as the iminodiacetate type. Chelating resins typically have three to four times less capacity than this IEM and are more costly than the strong acid resins.

\section{Applications}

Two applications where film IEM could be used are presented. In the first, real electroplating waste was treated in a batch test with IEM to see if anything in the waste interfered with the use of the IEM. In the second application, films were tested in a continuous processing simulation of drinking water purification or decontamination of waste from circuit board processing.

The studies of electroplating waste water illustrate how the IEM behaves in a mixture of metals having a complex matrix (table 2). As expected from the results of the $\mathrm{pH}$ study (fig. 3), the IEM is not very effective in removing metal ions at low $\mathrm{pH}$ values. However, it is effective in removing metal ions from a mixture at $\mathrm{pH}$ values of 5 and 7 . These $\mathrm{pH}$ values are significant in that the waste could be disposed of provided that all concentrations meet local permit levels. The IEM could easily be used in the final polishing stage to reduce metal concentrations to meet disposal limits. A kinetic study (similar to figs. 4 to 6) compared the electroplating waste water spiked with copper with the same concentration of copper in deionized water at the same $\mathrm{pH}$. The comparison indicated that there is a negligible difference between the rate of removal of copper or the equilibrium concentration of copper over the IEM, provided that the IEM has sufficient capacity to remove all metal ions. These properties are advantageous because they indicate that copper in the electroplating waste mixture having unknown components (attributable to brighteners, carriers, pretreating agents, etc.) and high levels of sodium ion will be removed in a manner similar to laboratory samples.

Table 3 presents the results of a column experiment that used a 3-ft rod wrapped with the IEM and had a residence time in the system of approximately $3 \mathrm{hr}$. In the first test, the concentration of $\mathrm{Pb}^{2+}$ was lowered by approximately 2 orders of magnitude. For comparison, a single sheet of IEM $(0.40 \mathrm{~g})$ was equilibrated with 1.01 of tap water fortified to 56-ppb $\mathrm{Pb}$ in a beaker test. After stirring for $2.5 \mathrm{hr}$ (simulating the 3-hr residence time in the column experiment), the IEM lowered the lead level to $1.5 \mathrm{ppb}$. In the second column test, the concentration of $\mathrm{Cu}^{2+}$ was lowered by approximately 4 orders of magnitude (see table 3). These experiments simulate the purification of drinking water. Figure 9 is a plot of the ratio of the effluent concentration $C_{e}$ to the influent concentration $C_{i}$ versus the volume of test solution passed through the column in a second experiment using the 1.5-ft rod. As shown in figure 9, the 
column experiment can be run effectively at considerably faster flow rates and with shorter columns. The importance of this result is that the film can be used in a flow process and that the calculated 50- $\mu \mathrm{m}$ flow channel is sufficiently large that particles are less likely to plug the system as would happen in a conventional packed column process. At the higher flow rates, mass transport to the IEM is the limiting factor in concentration reduction; however, there are many applications in which the concentration reduction need only be a factor of 2 so that this system could be used. Further, the amount of concentration reduction can be tuned to the required reduction dictated by the application. This type of column operation generated a negligible pressure drop across the column, suggesting that low- pressure equipment can be employed to effectively decontaminate solutions.

\section{Conclusion}

The ion-exchange material described in this paper is a weak acid that can exchange metal cations in general and has a high affinity for heavy metals such as lead and cadmium. The material has a high capacity. It is effective in the calcium form and can exchange metal ions from hard water. The optimum $\mathrm{pH}$ range is 5 to 7 . These properties are advantageous when working with water from natural systems. The material can be fabricated from ingredients that are readily available. It can be made into a variety of forms including films and particles, or it can be coated onto surfaces.

\section{References}

(1) Hill, C.M.; Street, K.W.; Philipp, W.H.; Tanner, S.P. Determination of Copper in Tap Water Using Solid Phase Spectrophotometry. Anal. Lett. 1994272589.

(2) Uy, O.M.; Ginther, M.J.; Folkerts, J.T.; Street, Jr., K.W. Use of a NASA-Developed Ion Exchange Material for Removal of Zinc from Electroplating Baths. Johns Hopkins APL Tech. Dig. 199617 371.

(3) Hill, C.M.; Street, K.W.; Philipp, W.H.; Tanner, S.P. Preparation of Ion Exchange Films for Solid Phase Spectrophotometry and Solid Phase Fluorometry. Anal. Lett. 2000332779.

(4) Street, Jr., K.W.; Hovanitz, E.; Chi, S. Lead Removal from Synthetic Leachate Matrices by a Novel Ion-Exchange Material. J. Air \& Waste Manage. Assoc. 2002521075.

(5) Philipp, W.H.; Street, K.W. Ion Exchange Polymers and Method for Making. U.S. Patent 5,371,110 1994.

(6) Schlameus, H.W.; Barlow, D.E. Method for Preparing Polymeric Beads. U.S. Patent 5,959,073 1999.

(7) Gao, L.T.; Seliskar, C.J.; Milstein, L. Spectroscopic Sensing with a Highly Transparent, IonExchangeable Polymer Blend. Appl. Spect. 1997511745.

(8) Talu, O.; Shah, D.B.; Sun, S.; Street, Jr., K.W.; Philipp, W.H.; Wan, W. A New Ion-Exchange Media for Heavy Metal Removal from Solutions and Slurries. National Meeting of the American Institute of Chemical Engineers, San Francisco, CA 1994.

(9) Talu, O.; Shah, D.B.; Sun, S.; Street, Jr., K.W.; Philipp, W.H.; Wan, W. Continuous Heavy Metal Removal from Solutions and Slurries by Films of a New Ion-Exchange Media. National Meeting of the American Institute of Chemical Engineers, San Francisco, CA 1994.

(10) Sengupta S.; Sengupta, A.K. Characterizing a New Class of Sorptive Ion Exchange Membranes for Decontamination of Heavy-Metal-Laden Sludges. Environ. Sci. Technol. 1993272133.

(11) U.S. Environmental Protection Agency, Proposed Update Number III: Physical/Chemical Methods Test Methods for Evaluating Solid Waste, SW-846; U.S. Government Printing Office: Washington, DC, 1994. 
(12) Tanner, S.P.; Street, Jr., K.W. Solid Phase Luminescence of Several Rare Earth Ions on IonExchange Films. Appl. Spect. 200054669.

(13) Sillén, L.G.; Martell, A. E. Stability Constants of Metal-Ion Complexes, second ed; Chemical Society: 1964.

(14) Nakamoto, K. Infrared and Raman Spectroscopy of Inorganic and Coordination Compounds, Part B, fifth ed.; John Wiley \& Sons: New York, 1997.

(15) Tackett, J.E. FT-IR Characterization of Metal Acetates in Aqueous Solution. Appl. Spect. 198943483.

(16) Riehman, W.; Walton, H.F. Ion Exchange in Analytical Chemistry; Pergamon: Oxford, 1970.

(17) Walton, H.F.; Rocklin, R.D. Ion Exchange in Analytical Chemistry; CRC Press: Boca Raton, FL, 1990.

TABLE 1.-HALFLIVES FOR METAL UPTAKE BY IEM

\begin{tabular}{|l|l|l|l|c|c|c|}
\hline Film & $\begin{array}{c}\text { Test } \\
\text { metal }\end{array}$ & $\mathrm{pH}$ & $\begin{array}{c}\text { Initial } \\
\text { concentration } \\
(\mathrm{ppm})\end{array}$ & $\begin{array}{c}\text { Percent } \\
\text { remaining }\end{array}$ & $\begin{array}{c}\text { Halflife, } \\
\text { (min) }\end{array}$ & $\begin{array}{c}\text { Hydrated } \\
\text { ionic } \\
\text { radii } \\
\text { (nm) }\end{array}$ \\
\hline $\mathrm{Ca}^{2+}$ & $\mathrm{Ag}^{+}$ & 5.5 & 14 & 36 & 23 & 0.25 \\
& $\mathrm{Cu}^{2+}$ & 5 & 14 & 0.1 & 54 & .6 \\
& $\mathrm{Zn}^{2+}$ & 5.5 & 16 & 0.4 to 5.4 & 47 & .6 \\
& $\mathrm{Cd}^{2+}$ & 5 & 15 & .5 & 45 & .5 \\
& $\mathrm{~Pb}^{2+}$ & 5.5 & 16 & $<.1$ & 23 & .45 \\
\hline $\mathrm{Na}^{+}$ & $\mathrm{Y}^{3+}$ & 5.5 & 11 & .4 & $>251$ & .9 \\
& $\mathrm{Ag}^{+}$ & 5.5 & 14 & 3.3 & 26 & 0.25 \\
& $\mathrm{Cu}^{2+}$ & 5 & 14 & 31 & 19 & .6 \\
& $\mathrm{Zn}^{2+}$ & 5.5 & 16 & 8.6 & 12 & .6 \\
& $\mathrm{Cd}^{2+}$ & 5 & 15 & 31 & 19 & .5 \\
& $\mathrm{~Pb}^{2+}$ & 5.5 & 16 & 8.8 & $<23$ & .45 \\
\hline $\mathrm{Ca}^{2+}$ & $\mathrm{Y}^{3+}$ & 5.5 & 11 & 33 & 32 & .9 \\
\hline $\mathrm{Cu}^{2+}+100-\mathrm{ppm} \mathrm{Ca}^{2+}$ & 5 & 14 & $<0.1$ & 75 & \\
\hline $\mathrm{Na}^{+}$ & $\mathrm{Cu}^{2+}+100-\mathrm{ppm} \mathrm{Ca}^{2+}$ & 5 & 16 & 4.3 & 90 & \\
\hline $\mathrm{Cd}^{2+}+100-\mathrm{ppm} \mathrm{Ca}^{2+}$ & 5 & 14 & $<0.1$ & 28 & \\
\hline
\end{tabular}

${ }^{\mathrm{a}} \mathrm{Hydrated}$ radii for $\mathrm{Ca}^{2+}$ and $\mathrm{Na}^{+}$are 0.60 and $0.45 \mathrm{~nm}$, respectively. 
TABLE 2.- METAL ION RECOVERIES FROM ELECTROPLATING WASTE SOLUTIONS

\begin{tabular}{|l|c|c|c|c|c|c|}
\hline \multirow{2}{*}{ Metal } & \multicolumn{2}{|c|}{$\mathrm{pH}=2$} & \multicolumn{2}{c|}{$\mathrm{pH}=5$} & \multicolumn{2}{c|}{${ }^{\mathrm{pH}}=7$} \\
\cline { 2 - 6 } & $\begin{array}{c}\text { Initial } \\
\text { concentration } \\
(\mathrm{ppm})\end{array}$ & $\begin{array}{c}\text { Percent } \\
\text { removed }\end{array}$ & $\begin{array}{c}\text { Initial } \\
\text { concentration } \\
\text { (ppm) }\end{array}$ & $\begin{array}{c}\text { Percent } \\
\text { removed }\end{array}$ & $\begin{array}{c}\text { Initial } \\
\text { concentration } \\
\text { (ppm) }\end{array}$ & $\begin{array}{c}\text { Percent } \\
\text { removed }\end{array}$ \\
\hline $\mathrm{Zn}$ & 23 & 5.5 & 8.38 & 98 & 8.38 & 96 \\
$\mathrm{Cd}$ & 0.94 & 4.3 & .88 & $\mathrm{~b}^{\mathrm{b}} 98$ & .88 & $\mathrm{~b}^{\mathrm{b}} 98$ \\
$\mathrm{Ni}$ & 3.26 & 4.9 & 1.11 & 82 & 1.11 & 82 \\
$\mathrm{Cu}$ & 5.39 & 1.1 & $(\mathrm{c})$ & $(\mathrm{c})$ & ${ }^{\mathrm{d}} 1.47$ & 94 \\
$\mathrm{Mn}$ & .22 & 9.1 & .22 & 95 & .22 & .87 \\
$\mathrm{Mg}^{\mathrm{e}}$ & 1.1 & 0 & .92 & 45 & $\mathrm{~b}^{\mathrm{b}} 99.6$ \\
\hline
\end{tabular}

${ }^{\mathrm{a}} \mathrm{For} \mathrm{pH}=7$, the following equilibrium concentrations in ppm were determined: $\mathrm{Ag}^{+}(0.01) ; \mathrm{Na}^{+}(1415)$; $\mathrm{Co}^{2+}(0.01) ; \mathrm{Cr}^{3+}(0.03) ; \mathrm{Fe}^{3+}(0.02)$.

${ }^{\mathrm{b}}$ Final concentration below level of detection. Recovery calculations based on detection limit.

${ }^{\mathrm{c}}$ Not determined.

${ }^{\mathrm{d}}$ Spiked to $1.47 \mathrm{ppm}$.

${ }^{\mathrm{e}}$ Magnesium data provided courtesy of Northeast Ohio Regional Sewer District.

TABLE 3.-PARAMETERS AND RESULTS FOR COLUMN EXPERIMENT SIMULATING DRINKING WATER PURIFICATION

\begin{tabular}{|l|c|c|}
\hline Experimental condition & Test 1 & Test 2 \\
\hline Challenge solution & $\mathrm{Pb}$ & $\mathrm{Cu}$ \\
Challenge (influent) concentration, $\mathrm{C}_{\mathrm{i}}$ & $142(\mathrm{ppb})$ & $16.8(\mathrm{ppm})$ \\
Run time (hr) & 46.5 & 19 \\
Volume processed (ml) & 279 & 114 \\
Effluent concentration, $\mathrm{C}_{\mathrm{e}}$ & $2.1 \pm 0.6(\mathrm{ppb})$ & $0.002(\mathrm{ppm})$ \\
Fraction of original copper & 0.015 & 0.00012 \\
$\quad$ concentration & & \\
in column effluent, $\mathrm{C}_{\mathrm{e}} / \mathrm{C}_{\mathrm{i}}$ & & 1 \\
Data points beyond void volume & 6 & \\
\hline
\end{tabular}




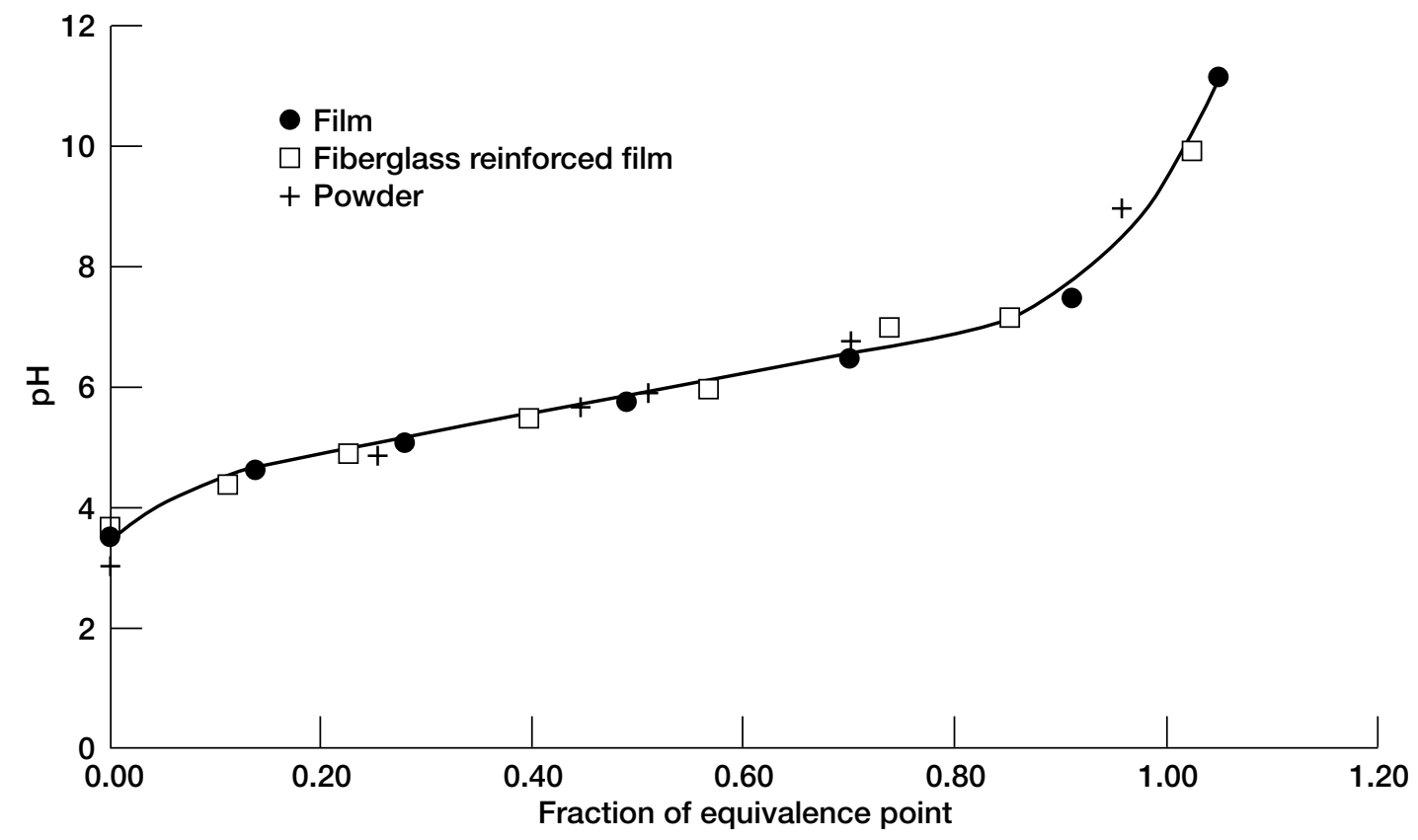

Figure 1.-Equilibrium pH over IEM film at various stages of conversion from acid form to salt form. Also shown for comparison are formaldehyde cross-linked IEM film, glutaraldehyde cross-linked fiberglass-reinforced IEM film (Chemsultants), and glutaraldehyde cross-linked IEM powder (Southwest Texas Research Institute).

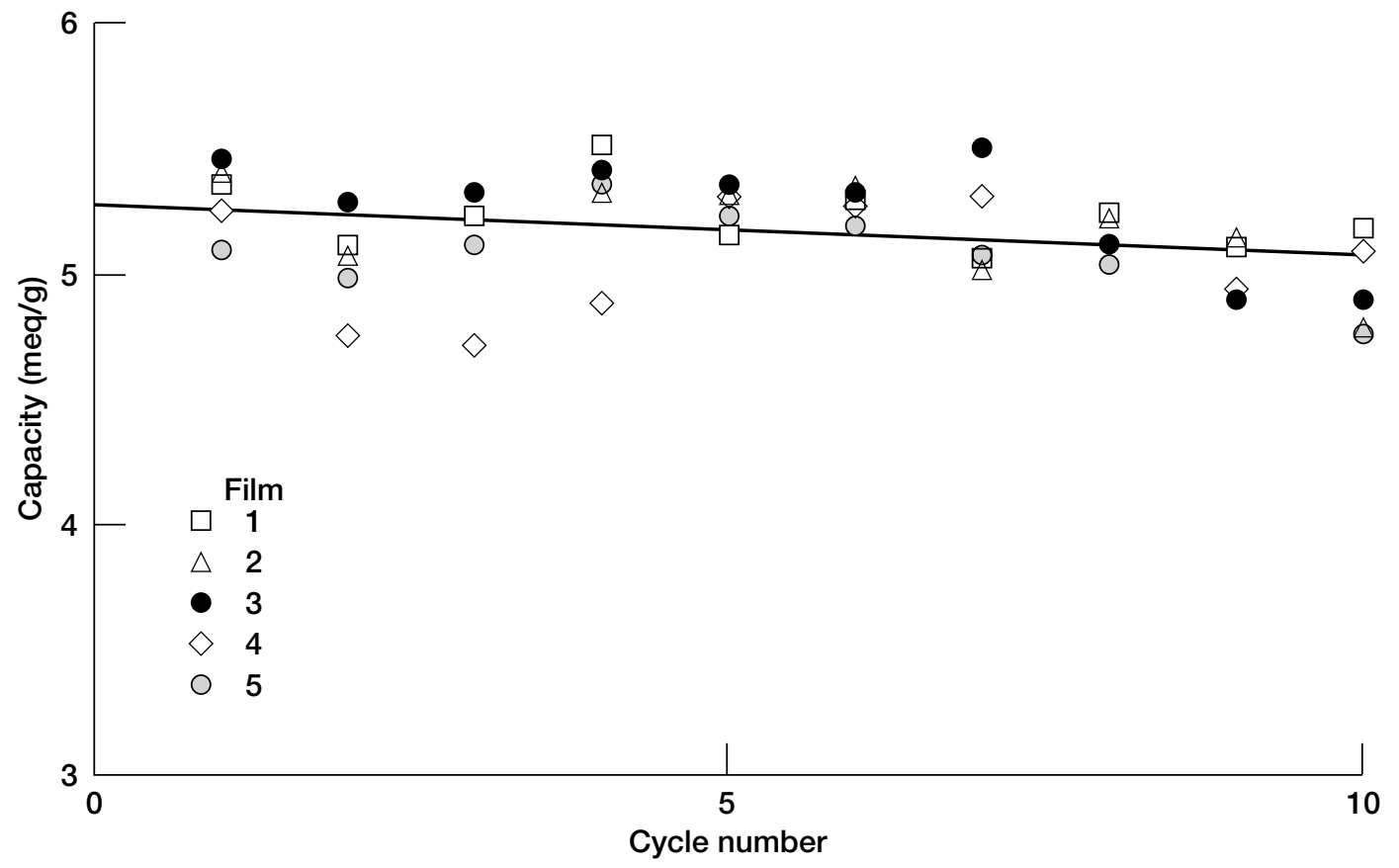

Figure 2.-Capacity of IEM film as function of cycling between acid and calcium forms of IEM. 


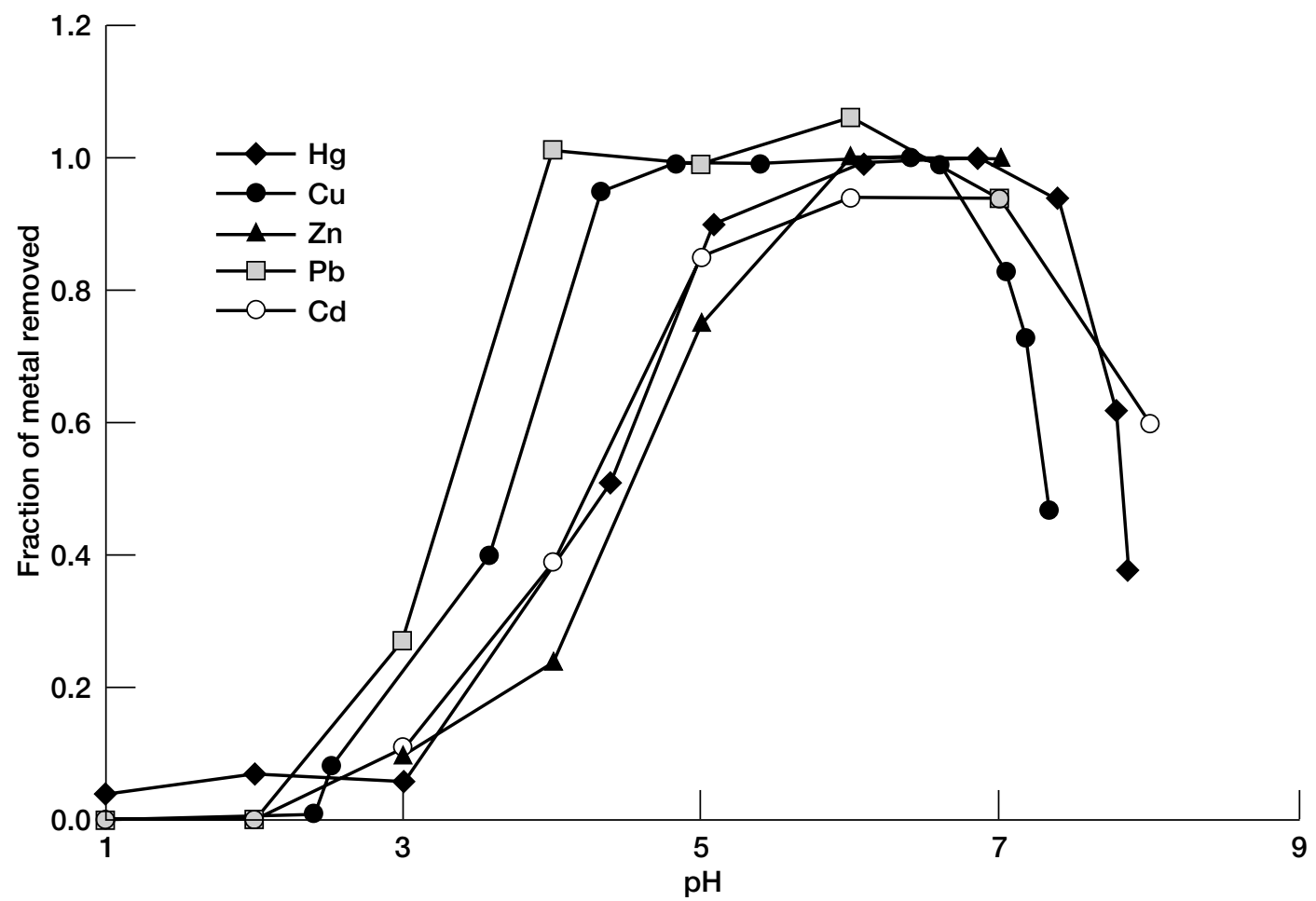

Figure 3.- $\mathrm{pH}$ dependence on fraction of metal removed from solution into IEM for mercury, copper, zinc, lead, and cadmium.

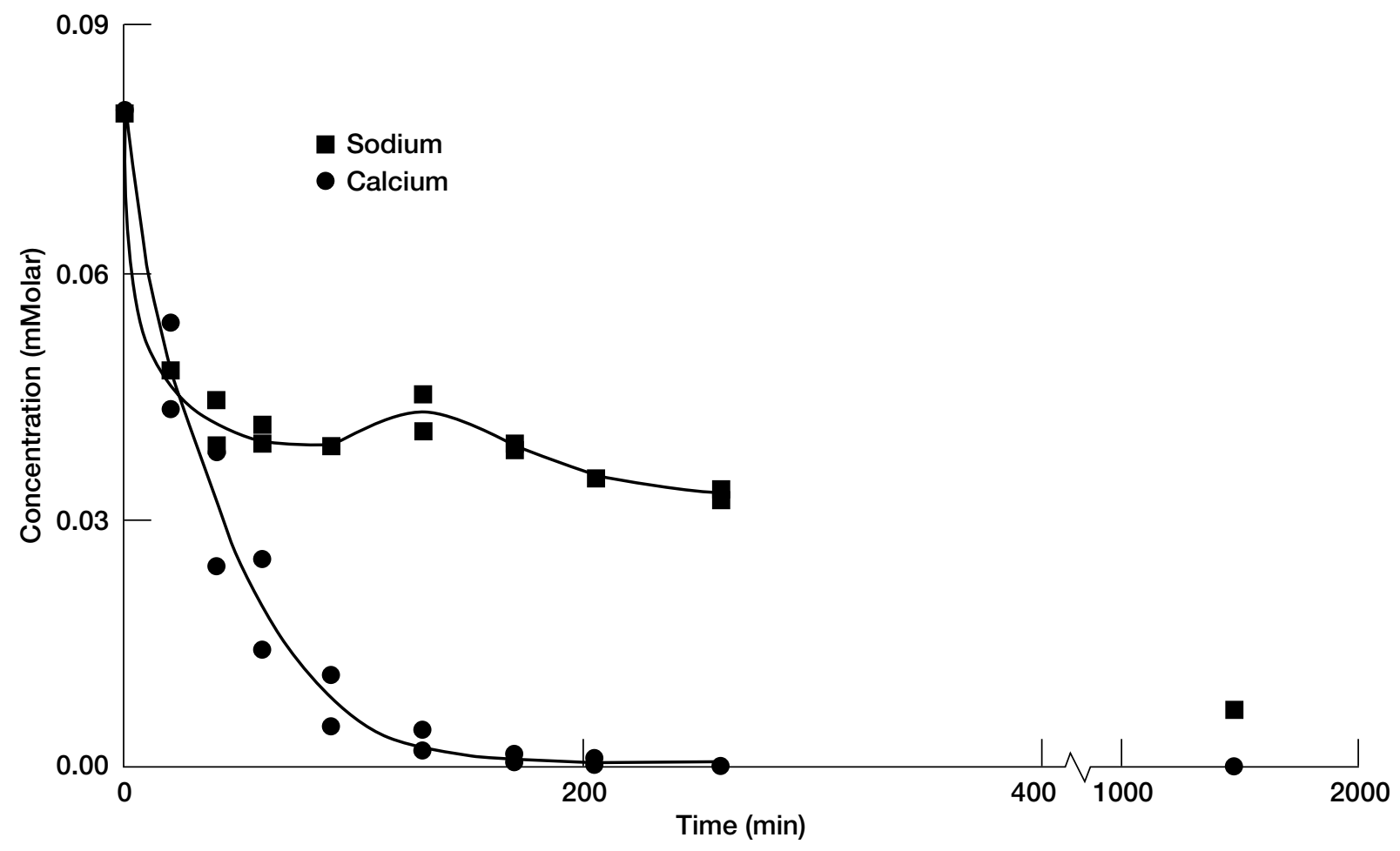

Figure 4.-Lead concentration remaining in solution over IEM as function of equilibration time for sodium and calcium films. Note: Each experiment in duplicate on different days, (i.e., four different film experiments). 


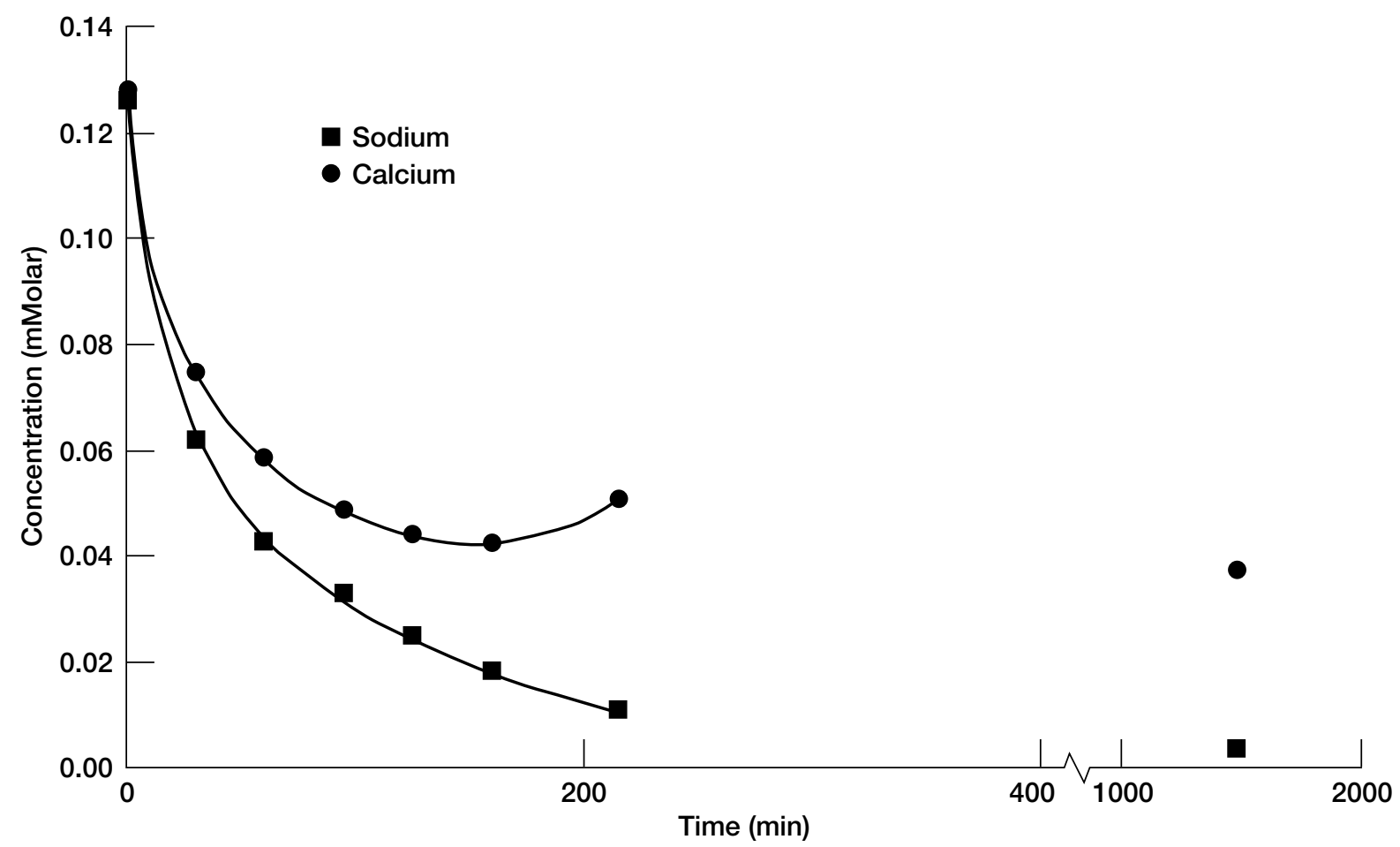

Figure 5.-Silver concentration remaining in solution over IEM as function of equilibration time for sodium and calcium films.

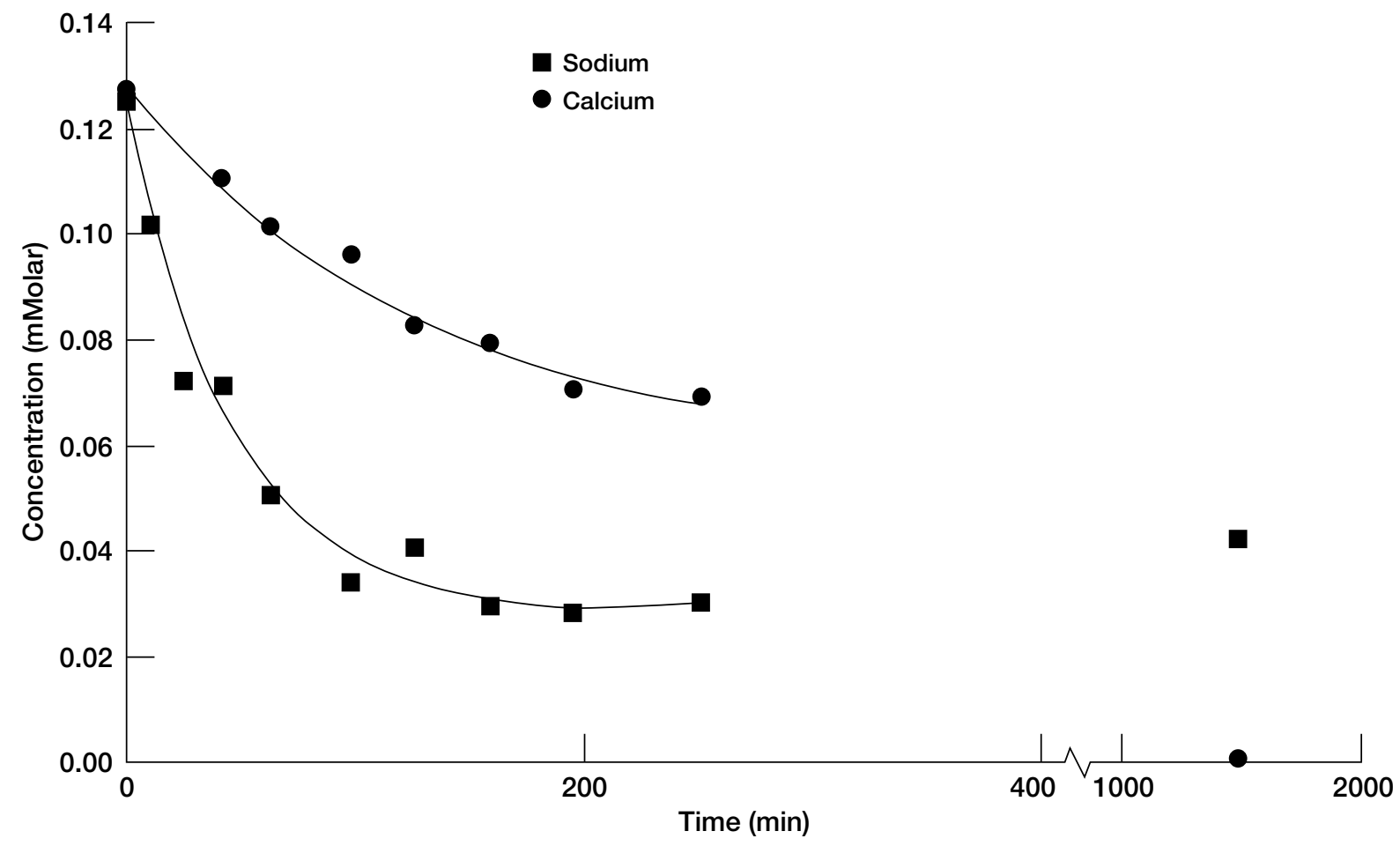

Figure 6.-Yttrium concentration remaining in solution over IEM as function of equilibration time for sodium and calcium films. 


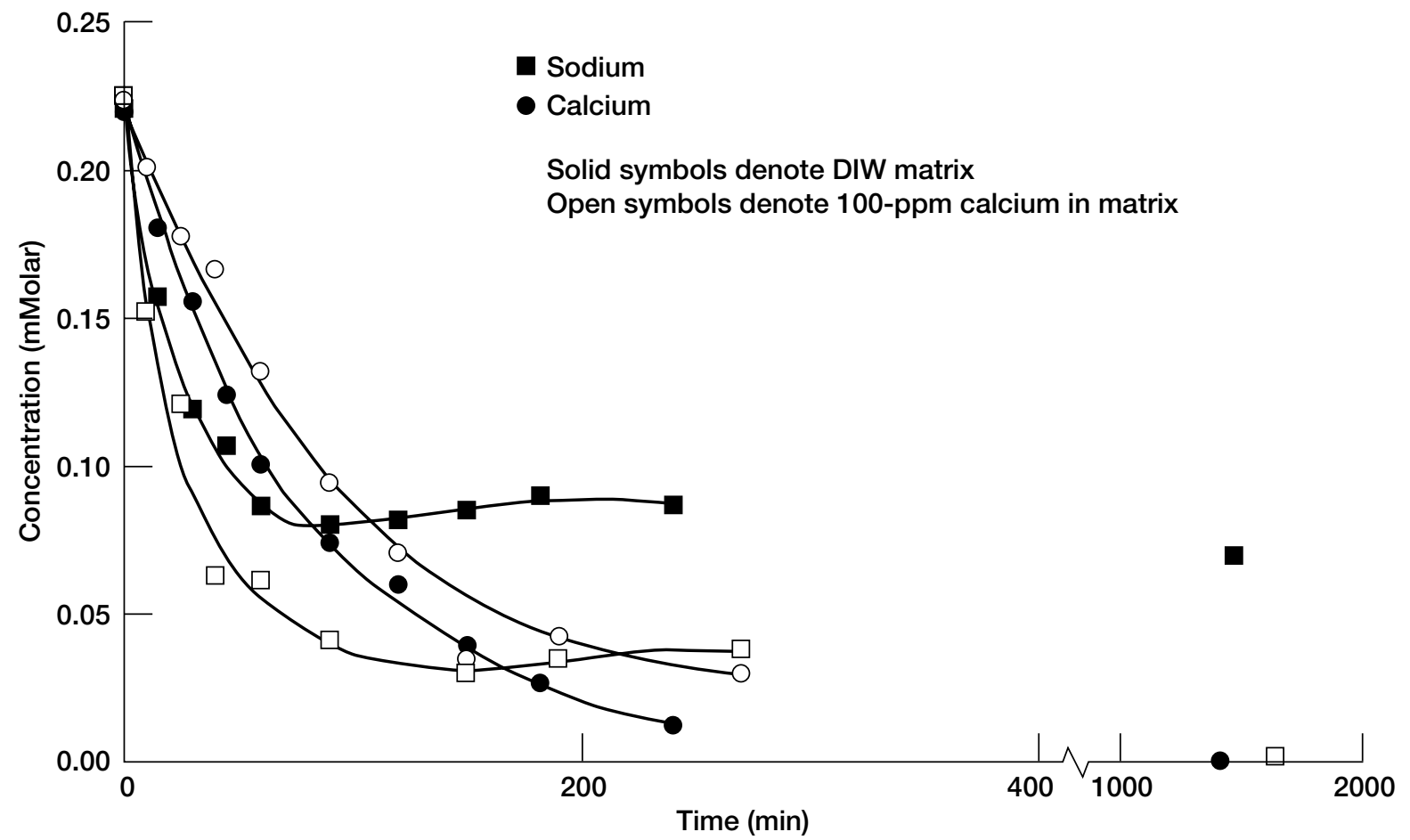

Figure 7.-Copper concentration remaining in solution over IEM as function of equilibration time for sodium and calcium films.

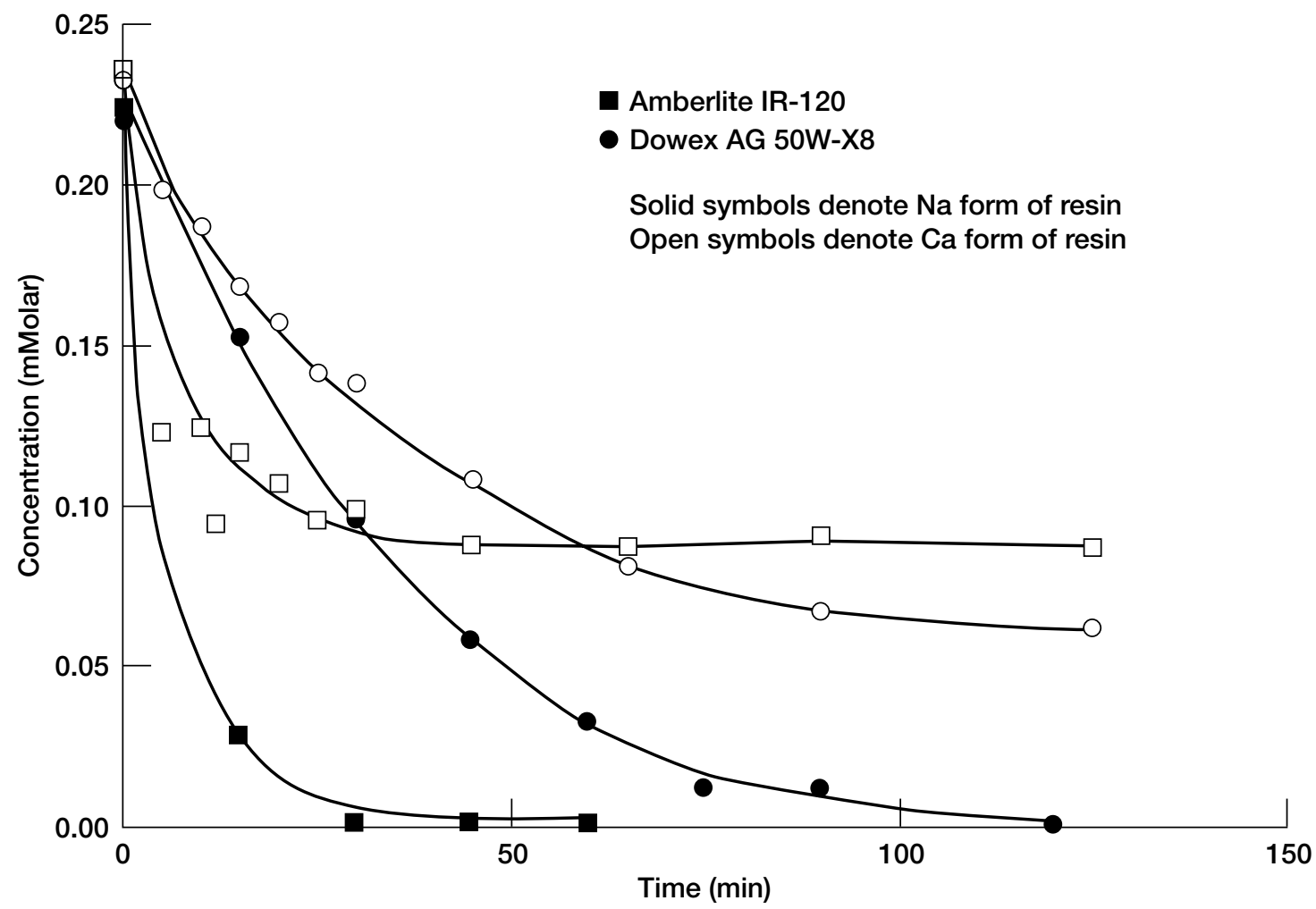

Figure 8.-Copper concentration remaining in solution over commercial resins as function of equilibration time. 


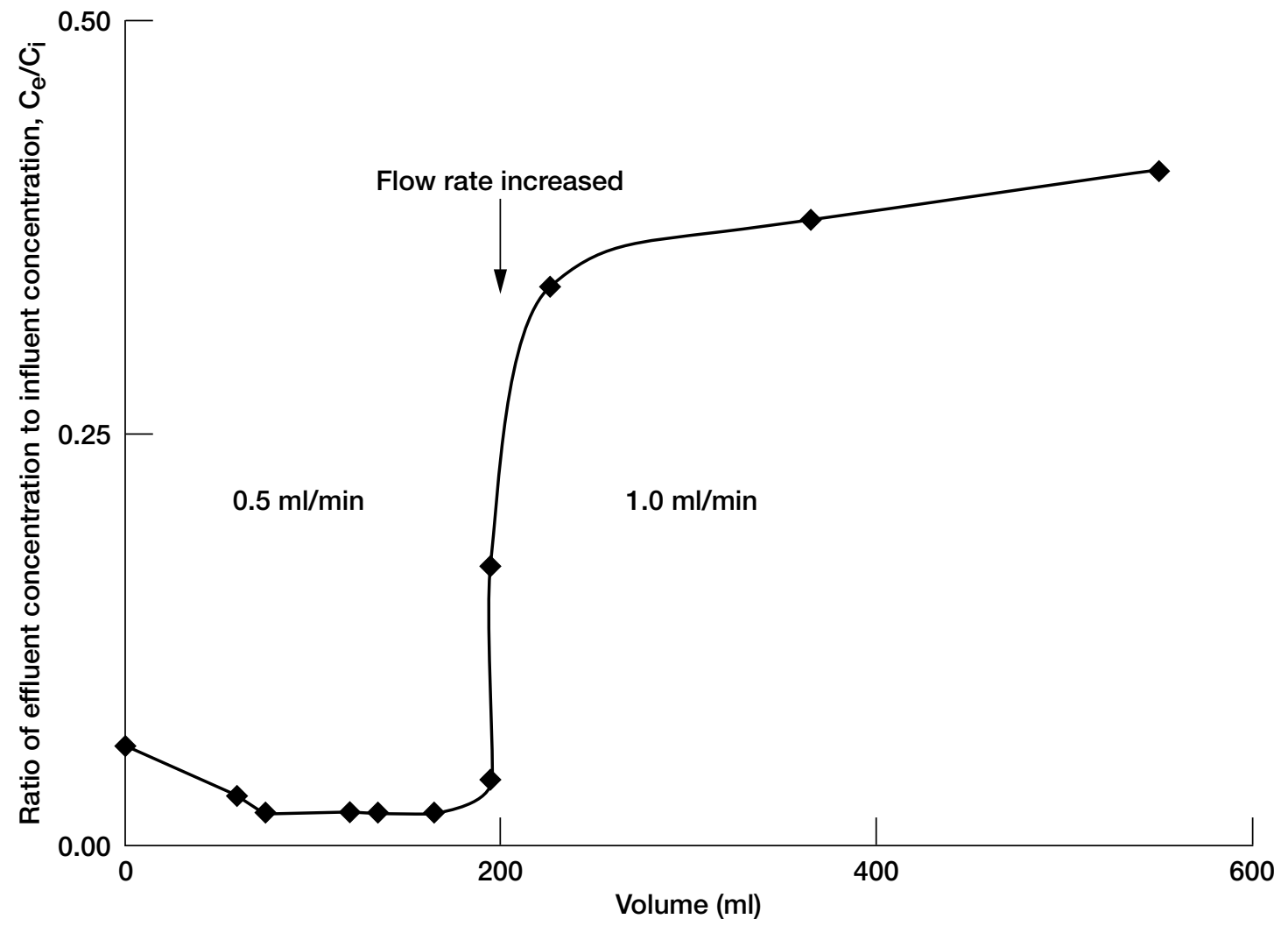

Figure 9.-Fraction of original copper concentration in column effluent, $C_{e} / C_{i}$, versus volume of test solution passed through column. Influent concentration, $\mathrm{C}_{\mathrm{i}}, 9.0 \mathrm{ppm}$. 


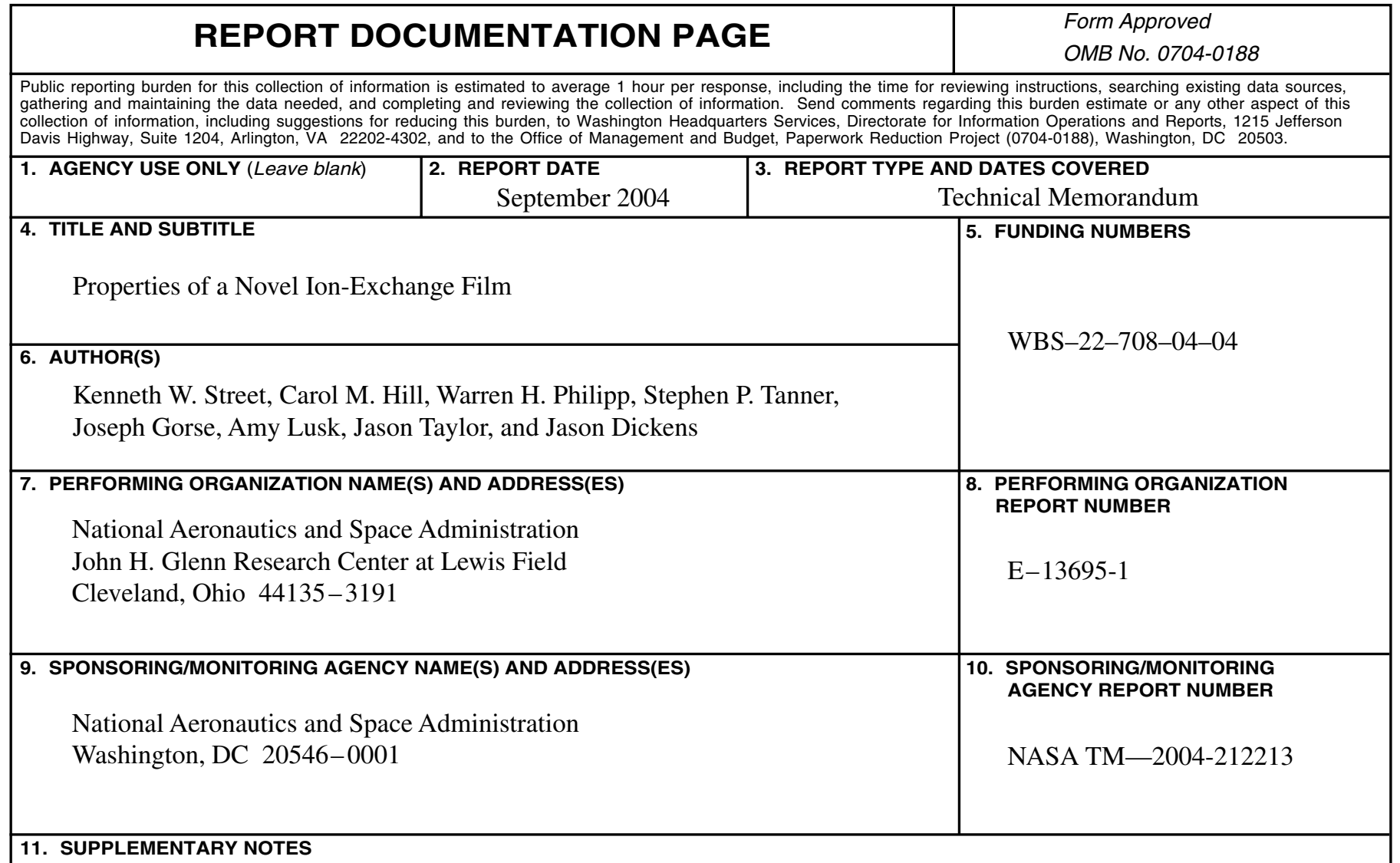

Kenneth W. Street, Carol M. Hill, and Warren H. Philipp, NASA Glenn Research Center; Stephen P. Tanner, University of West Florida, Department of Chemistry, 11000 University Parkway, Pensacola, Florida 32514-5751; and Joseph Gorse, Amy Lusk, Jason Taylor, and Jason Dickens, Baldwin Wallace College, Department of Chemistry, Berea, Ohio 44017-2005. Responsible person, Kenneth W. Street, organization code 5960, 216-433-5032.

\begin{tabular}{|l|l}
\hline 12a. DISTRIBUTION/AVAILABILITY STATEMENT & 12b. DISTRIBUTION CODE
\end{tabular}

Unclassified - Unlimited

Subject Category: 45

Distribution: Nonstandard

Available electronically at http://gltrs.grc.nasa.gov

This publication is available from the NASA Center for AeroSpace Information, 301-621-0390.

\section{ABSTRACT (Maximum 200 words)}

A new ion-exchange material (based on polyacrylic acid) and some of its analytical applications have been reported. This paper contains data on the ion-exchange properties of the film form of the material and its potential application to the decontamination of waste water and drinking water. The film has a high exchange capacity of 5 to 6 meq/g and a $\mathrm{pK}_{\mathrm{a}}$ of 5.7. The calcium form is the most effective for removing metal ions from solution, and the optimum $\mathrm{pH}$ range is between 5 and 7. The exchange rates are slower for the film than for bead and powder forms of the ion-exchange material; otherwise, the properties are similar. The film is effective when hard water solutions are employed and also when metal ions are in the complex matrix of waste water from electroplating. The film can be used in flow systems having a flow channel large enough to allow passage of turbid solutions.

\begin{tabular}{|c|c|c|}
\hline \multicolumn{3}{|l|}{$\begin{array}{l}\text { 14. SUBJECT TERMS } \\
\text { Ion-exchange film. Wa }\end{array}$} \\
\hline $\begin{array}{l}\text { 17. SECURITY CLASSIFICATION } \\
\text { OF REPORT } \\
\text { Unclassified }\end{array}$ & $\begin{array}{l}\text { 18. SECURITY CLASSIFICATION } \\
\text { OF THIS PAGE }\end{array}$ & $\begin{array}{l}\text { 19. SECURITY CLASSIFICATION } \\
\text { OF ABSTRACT }\end{array}$ \\
\hline Unclassı11ed & Unclassified & Unclassif1ed \\
\hline
\end{tabular}

NSN 7540-01-280-5500 

